\title{
Dexmedetomidine in combination with morphine PCA provides superior analgesia for shockwave lithotripsy
}

\author{
[La dexmédétomidine combinée à la morphine en $A A C$ fournit une analgésie \\ supérieure pour la lithotripsie par ondes de choc]
}

Jamal A. Alhashemi MBBS MSc FRCPC FCCP, Abdullah M. Kaki MBBS FRCPC

Purpose: To compare the analgesic effects of dexmedetomidine/morphine with those of tramadol/midazolam in patients undergoing extracorporeal shockwave lithotripsy (ESWL) for urinary calculi.

Methods: Sixty patients were randomized to receive either dexmedetomidine I $\mu \mathrm{g} \cdot \mathrm{kg}^{-1}$ iv followed by $0.5 \mu \mathrm{g} \cdot \mathrm{kg}^{-1} \cdot \mathrm{hr}^{-1}$ infusion together with morphine patient-controlled analgesia [(PCA); 2 mg bolus, five minutes lockout, $2 \mathrm{mg} \cdot \mathrm{hr}^{-1}$ infusion; (Group DEX)], or tramadol $1.5 \mathrm{mg} \cdot \mathrm{kg}^{-1}$ pre-mixed with midazolam $30 \mu \mathrm{g} \cdot \mathrm{kg}^{-1}$ iv followed by tramadol PCA [20 mg bolus, five minute lockout, 20 $\mathrm{mg} \cdot \mathrm{hr}^{-1}$ infusion; (Group TRA)]. Pain was assessed at baseline and every 15 min thereafter. Patients' and urologist's satisfaction with analgesia and sedation were determined on a seven-point scale ranging from I (extremely dissatisfied) to 7 (extremely satisfied). Patient's discharge time was also documented.

Results: Visual analogue scale scores over time were consistently lower in Group DEX compared with Group TRA $(P=0.001)$. Patients' satisfaction with analgesia ( $5 \pm 1$ vs $4 \pm 2, P=0.012$ ) and with sedation ( $6 \pm 1$ vs $5 \pm 1, P=0.020)$, and urologist's satisfaction ( $6 \pm$ I vs $4 \pm 2, P=0.00$ I) were all higher amongst Group DEX patients compared with Group TRA. There was no difference between discharge times of patients in Group DEX compared with those in Group TRA $[85(60,115)$ min vs $65(40,95) \mathrm{min}, P=$ 0.069].

Conclusion: Dexmedetomidine in combination with morphine PCA provided better analgesia for ESWL and was associated with higher patients' and urologist's satisfaction when compared with a tramadol/midazolam PCA combination.
Objectif : Comparer les effets analgésiques des dexmédétomidine/morphine combinées avec ceux d'un mélange tramadol/midazolam chez des patients qui subissent une lithotripsie extracorporelle par ondes de choc (LEOC) pour calculs urinaires.

Méthode : Soixante patients ont été répartis au hasard dans le groupe DEX pour recevoir I $\mu \mathrm{g} \cdot \mathrm{kg}^{-1}$ de dexmédétomidine iv suivi d'une perfusion à $0,5 \mu \mathrm{g} \cdot \mathrm{kg}^{-1} \cdot \mathrm{h}^{-1}$ combinée à de la morphine en analgésie autocontrôlée (AAC) ; [bolus de $2 \mathrm{mg}$, une période réfractaire de cinq minutes, une perfusion de $2 \mathrm{mg} \cdot \mathrm{h}^{-1}$ ] ou dans le groupe TRA recevant I,5 mg. $\mathrm{kg}^{-1}$ de tramadol prémélangé avec $30 \mu \mathrm{g}^{\mathrm{kg}}{ }^{-1}$ de midazolam iv suivi de tramadol en AAC [bolus de 20 mg, période réfractaire de cinq minutes, perfusion à $20 \mathrm{mg} \cdot \mathrm{h}^{-1}$ ]. La douleur a été évaluée au départ et toutes les 15 min par la suite. Le degré de satisfaction des patients et de l'urologue concernant l'analgésie et la sédation a été évalué sur une échelle en sept points de 1 (très insatisfait) à 7 (très satisfait). Le moment du congé a été aussi noté.

Résultats : Les scores de l'échelle visuelle analogique ont été constamment plus bas chez les patients du Groupe DEX comparé au Groupe TRA $(P=0,001)$. Le degré de satisfaction des patients face à l'analgésie ( $5 \pm 1$ vs $4 \pm 2, P=0,012)$ et à la sédation ( $6 \pm 1$ vs $5 \pm 1, P=0,020)$, et celui de l'urologue ( $6 \pm 1$ vs $4 \pm 2, P=$ $0,001)$ ont été plus élevés parmi les patients du Groupe DEX. Les patients des deux groupes ont reçu leur congé selon des délais comparables : Groupe DEX comparé au Groupe TRA [85 $(60,115)$ min vs $65(40,95) \min , P=0,069]$

Conclusion : La dexmédétomidine combinée à la morphine en AAC fournit une meilleure analgésie pour la LEOC, et est associée à un plus haut degré de satisfaction des patients et de l'urologue, que le mélange en AAC de tramadol/midazolam.

From the Department of Anesthesia and Critical Care Medicine, King Abdulaziz University, King Abdulaziz University Hospital, Jeddah, Saudi Arabia.

Address correspondence to: Dr. Jamal A. Alhashemi, P.O. Box 31648, Jeddah 21418, Saudi Arabia. Phone: +966-2-6408335;

Fax: +966-2-6408336; E-mail: jalhashemi@kaau.edu.sa

Supported in part by departmental research fund.

Accepted for publication July 8, 2003.

Revision accepted November 28, 2003. 


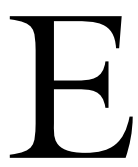

XTRACORPOREAL shockwave lithotripsy (ESWL) is widely used for the treatment of urinary tract calculi; however, the vast majority of patients do not tolerate the procedure without analgesia and sedation. Several monitored anesthesia care techniques have been used to provide such sedation and analgesia. ${ }^{1-4}$ However, most of the analgesic drugs administered for ESWL carry the risk of respiratory depression, delayed discharge, and/or unplanned hospital admission. Dexmedetomidine and tramadol, in contrast, are two drugs that possess analgesic properties, and yet are devoid of respiratory depressant effects. ${ }^{5-8}$ They, therefore, have a potential advantage over currently available analgesic agents used for ESWL.

Although dexmedetomidine has both sedative and analgesic properties, many patients who receive this drug require supplemental analgesia. ${ }^{9}$ In contrast, tramadol posseses significant analgesic effects but has minimal sedative properties. ${ }^{10}$ Therefore, either drug alone would not be sufficient to provide both analgesia and sedation for ESWL patients. Accordingly, an analgesic drug would have to be added to dexmedetomidine, and a sedative agent to tramadol to provide drug combinations that would be suitable for patients undergoing ESWL. This randomized, double-blind, clinical study was undertaken to compare the analgesic effects of a dexmedetomidine/morphine combination with those of a tramadol/midazolam combination in patients undergoing ESWL for urinary tract calculi.

\section{Methods}

After institutional Ethics Committee approval, 60 American Society of Anesthesiologists' physical class I to II patients gave written informed consent to participate in this randomized, double-blind, clinical trial. Patients were included in the study if they were 18-80 yr of age, had renal, ureteric, or bladder stones, and were scheduled for ESWL. Patients were excluded from the trial if they had any of the following: 1) serum creatinine $>200 \mu \mathrm{mol} \cdot \mathrm{L}^{-1} ; 2$ ) history of chronic use of analgesic and/or sedative drugs; or 3) allergy to any of the study medications. Using a computergenerated randomization schedule, patients were randomized to one of two groups; dexmedetomidine (DEX) or tramadol (TRA). All patients' assessments were performed by one individual who was blinded to the patient group assignment.

All patients received no premedication and were asked to position themselves on the lithotriptor table (Dornier Lithotriptor U/15, Daimler-Benz Aerospace, Germering, Germany). Standard monitors including electrocardiogram (ECG), noninvasive blood pressure, and pulse oximeter were applied (Dinamap $^{\mathrm{TM}}$ Plus, Critikon Inc., Tampa, FL, USA), and supplemental oxygen at $2 \mathrm{~L} \cdot \mathrm{min}^{-1}$ was administered via nasal prongs. In addition, the A-line ${ }^{\mathrm{TM}}$ monitor (Danmeter A/S, Odense, Denmark) was applied to determine the patient's level of sedation expressed as the A-line ARX index (AAI). ${ }^{11,12}$ Briefly, this device extracts the mid-latency auditory evoked potentials (AEP) from the electroencephalographic signal of the patient using an autoregressive model with an exogenous input (ARX) adaptive method that enables extraction of the AEP within 15 to 25 sweeps, needing only two to six seconds. The AAI is then calculated from this AEP wave. Heart rate (HR), systolic blood pressure (SBP), diastolic (DBP), and mean arterial pressures (MAP), oxygen saturation $\left(\mathrm{SpO}_{2}\right)$, and AAI values were measured at baseline and every five minutes thereafter until the end of the ESWL session. Patients in Group DEX received dexmedetomidine 1 $\mu \mathrm{g} \cdot \mathrm{kg}^{-1} i v$ over ten minutes followed by a continuous infusion of dexmedetomidine $0.5 \mu \mathrm{g} \cdot \mathrm{kg}^{-1} \cdot \mathrm{hr}^{-1}$. In addition, supplemental morphine was provided via patient-controlled analgesia (PCA) (IVAC PCAM $^{\mathrm{TM}}$, Alaris Medical Systems, Hampshire, UK) using the following settings: PCA dose $2 \mathrm{mg}$, lockout time five minutes, and continuous infusion $2 \mathrm{mg} \cdot \mathrm{hr}^{-1}$. In contrast, Group TRA patients received tramadol 1.5 $\mathrm{mg} \cdot \mathrm{kg}^{-1} i v$ over ten minutes premixed with midazolam $30 \mu \mathrm{g} \cdot \mathrm{kg}^{-1}$. This was followed by a continuous infusion of normal saline as placebo. In addition, tramadol PCA was started using the following settings: PCA dose $20 \mathrm{mg}$, lockout time five minutes, and continuous infusion $20 \mathrm{mg} \cdot \mathrm{hr}^{-1}$. In both groups, ESWL was started after the loading dose of the study medication was administered. Patient's pain was assessed at baseline and every $15 \mathrm{~min}$ thereafter using a visual analogue scale (VAS) ruler with two anchor points; zero

TABLE I Baseline characteristics

\begin{tabular}{lll}
\hline & $\begin{array}{l}\text { Group DEX } \\
(n=30)\end{array}$ & $\begin{array}{l}\text { Group TRA } \\
(n=30)\end{array}$ \\
\hline Age $(\mathrm{yr})$ & $50.1 \pm 14.4$ & $42.8 \pm 11.0^{*}$ \\
Weight $(\mathrm{kg})$ & $80.3 \pm 15.2$ & $78.3 \pm 20.3$ \\
Height $(\mathrm{cm})$ & $162.2 \pm 8.5$ & $163.8 \pm 5.4$ \\
Gender $(\mathrm{M} / \mathrm{F})$ & $23 / 7$ & $26 / 4$ \\
ASA Class $(\mathrm{I} / \mathrm{II})$ & $23 / 7$ & $25 / 5$ \\
Stone location $(\mathrm{renal} / \mathrm{ureter} /$ bladder $)$ & $24 / 6 / 0$ & $23 / 6 / 1$ \\
Session duration $(\mathrm{min})$ & $46.3 \pm 10.0$ & $46.3 \pm 12.0$ \\
Hypertension $(n)$ & 6 & 4 \\
Diabetes mellitus $(n)$ & 4 & 2 \\
\hline
\end{tabular}

Data presented as mean $\pm \mathrm{SD}$ or as numbers, as appropriate. ${ }^{*} P=$ 0.03 , different from Group DEX. DEX = dexmedetomidine; TRA $=$ tramadol. 
TABLE II Secondary outcomes

\begin{tabular}{lllll}
\hline & $\begin{array}{l}\text { Group DEX } \\
(n=30)\end{array}$ & $\begin{array}{l}\text { Group TRA } \\
(n=30)\end{array}$ & P value & $\begin{array}{l}95 \% \text { CI } \\
\text { DEX-TRA }\end{array}$ \\
\hline PCA demands $^{\mathrm{a}}(n)$ & $19(2,81)$ & $82(40,187)$ & 0.005 & $(10,87)$ \\
PCA drug administered $(\mathrm{mg})$ & $5.8 \pm 4.4$ & $9.2 \pm 3.6^{\mathrm{b}}$ & 0.001 & $(-5.5,-1.4)$ \\
Rescue treatment $(\mathrm{mg})$ & $0.3 \pm 1.2$ & $3.5 \pm 4.9^{\mathrm{b}}$ & 0.001 & $(-5.0,-1.3)$ \\
Shockwaves/patient $(n)$ & $3331 \pm 806$ & $3059 \pm 681$ & 0.160 & $(-111,655)$ \\
Shockwave intensity $(\%)$ & $90(80,98)$ & $80(70,90)$ & 0.020 & $(-15,0)$ \\
Patient satisfaction with sedation & $6 \pm 1$ & $5 \pm 1$ & 0.020 & $(0.1,1.4)$ \\
Patient satisfaction with analgesia & $5 \pm 1$ & $4 \pm 2$ & 0.012 & $(0.2,1.7)$ \\
Surgeon satisfaction with & $6 \pm 1$ & $4 \pm 2$ & 0.001 & $(0.5,2.1)$ \\
sedation and analgesia & & & & $(0.01,40.0)$ \\
Recovery time $^{\mathrm{a}}$ (min) & $85(60,115)$ & $65(40,95)$ & 0.069 & \\
\hline
\end{tabular}

Data presented as mean $\pm \mathrm{SD}$, unless otherwise indicated. $\mathrm{DEX}=$ dexmedetomidine; $\mathrm{TRA}=$ tramadol; $\mathrm{CI}=$ confidence interval; $\mathrm{PCA}=$

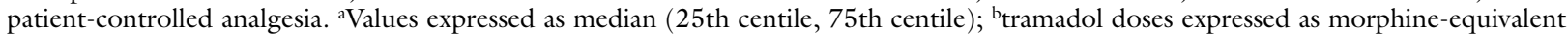
doses using a tramadol:morphine potency ratio of $1: 10$.

being no pain and ten being the worst pain the patient had ever experienced. Rescue medications in the form of morphine $5 \mathrm{mg}$ iv prn and tramadol $50 \mathrm{mg}$ iv prn were administered to Group DEX and Group TRA patients, respectively, if the surgeon had to temporarily stop the shock waves and/or decrease their intensity to $\leq 40 \%$ because of patient's movement from pain. Rescue medications were also administered if the patient's VAS score was $\geq \mathbf{5}$.

At the conclusion of the ESWL session and before they were moved to the recovery area, patients were asked to rate their satisfaction with the levels of sedation and analgesia they had received, each on a sevenpoint scale; one being extremely dissatisfied and seven being extremely satisfied. The urologist, who was blinded to the patient group assignment, was also asked to rate his satisfaction with the patient's tolerance of ESWL on a seven-point scale; one being extremely dissatisfied and seven being extremely satisfied. The Observer's Assessment of Alertness and Sedation $(\mathrm{OAA} / \mathrm{S})$ scale $^{13}$ and Trieger's dot (TD) test ${ }^{14}$ were performed at baseline and on admission to the recovery area after ESWL and every $30 \mathrm{~min}$ thereafter until discharge. Patients' discharge times and all adverse events were recorded.

\section{Statistical analysis}

Based on a two-sided alpha of 0.05 , a population variance of 2 , and a difference in VAS scores of 2 between the two study groups, a minimum of 23 patients were required per group to achieve a statistical power of $90 \%$ for this study. Repeated measures analysis of variance (RM-ANOVA) was used to analyze the primary outcome measure, VAS score, and the following sec- ondary outcomes: $\mathrm{HR}, \mathrm{SBP}, \mathrm{DBP}, \mathrm{MAP}, \mathrm{SpO}_{2}$, AAI values, OAA/S score, and TD test. Unpaired t test was used to analyze patients' and surgeons' satisfaction scores, the total amounts of analgesics administered via the PCA machine and as rescue treatment, the number of PCA demands, the number of shock waves delivered, shockwave intensity, and patients' recovery time. Any imbalance in patients' characteristics was adjusted for by adding the variable in question as a covariate to the RM-ANOVA procedure or by performing a multivariable regression analysis that included the imbalanced variable as an independent variable. All statistical procedures were performed using SPSS ${ }^{\circledR}$ statistical software (SPSS Inc., Chicago, IL, USA), version 9.0 for Windows. Results throughout the text, tables, and figures are presented as mean \pm SD unless otherwise specified and statistical significance was defined as $P<0.05$.

\section{Results}

There were no differences in baseline characteristics between the study groups other than an imbalance in age $(P=0.03$; Table I). Patients in Group DEX had lower VAS scores over time compared with patients in Group TRA $(P=0.001$; Figure 1$)$. These differences in VAS scores persisted after adjusting for the potential confounding effect of age $(P=0.008)$. There were also significant differences in the number of PCA attempts made between the two groups $(P=0.005$; Table II). When the total dose of tramadol administered by the patient via the PCA device was expressed as a morphine-equivalent dose (based on a morphine:tramadol potency ratio of $1: 10),{ }^{10}$ patients in Group TRA required more analgesia compared with 
TABLE III Psychomotor evaluation

\begin{tabular}{|c|c|c|}
\hline & $\begin{array}{l}\text { Group DEX } \\
(n=30)\end{array}$ & $\begin{array}{l}\text { Group TRA } \\
(n=30)\end{array}$ \\
\hline \multicolumn{3}{|l|}{ OAA/S score: } \\
\hline Baseline $^{\mathrm{a}}$ & $5(5,5)$ & $5(5,5)$ \\
\hline Immediate recovery $^{\mathrm{a}}$ & $5(4,5)$ & $5(5,5)$ \\
\hline $30 \mathrm{~min}$ in recovery ${ }^{\mathrm{a}}$ & $4(4,5)^{*}$ & $5(5,5)$ \\
\hline $60 \mathrm{~min}$ in recovery ${ }^{\mathrm{a}}$ & $5(5,5)$ & $5(5,5)$ \\
\hline \multicolumn{3}{|c|}{ Trieger's dot test (dots missed): } \\
\hline Baseline $(n)$ & $4 \pm 5$ & $5 \pm 5$ \\
\hline Immediate recovery $(n)$ & $12 \pm 10$ & $9 \pm 6$ \\
\hline $30 \mathrm{~min}$ in recovery $(n)$ & $9 \pm 6$ & $8 \pm 7$ \\
\hline $60 \mathrm{~min}$ in recovery $(n)$ & $5 \pm 5$ & $7 \pm 6$ \\
\hline
\end{tabular}

Data presented as mean $\pm \mathrm{SD}$, unless otherwise indicated. $\mathrm{DEX}=$ dexmedetomidine; TRA $=$ tramadol; OAA $/ S=$ Observer's Assessment of Alertness and Sedation. ${ }^{a}$ Values expressed as median (25th centile, 75 th centile). ${ }^{*} P=0.021$, different from group TRA.

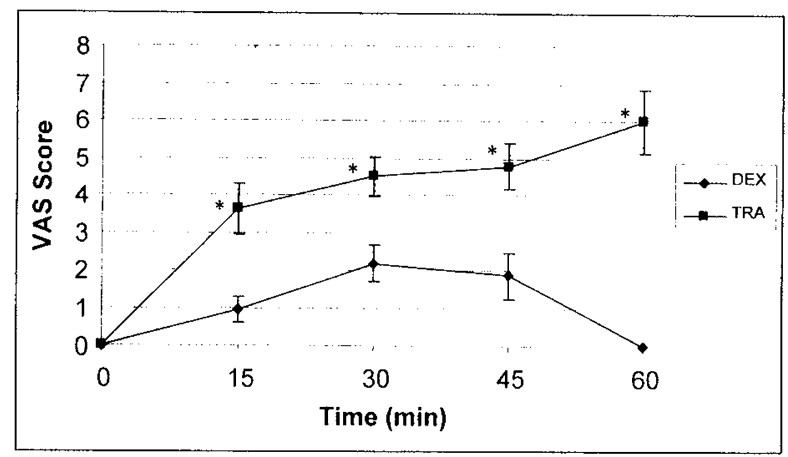

FIGURE 1 Changes in visual analogue scale (VAS) score over time. Data shown as means $\pm \mathrm{SD}$. ${ }^{*} P<0.05$, different from the corresponding data point in group DEX. DEX $=$ dexmedetomidine; TRA = tramadol.

those in Group DEX $(P=0.001)$. In addition, more rescue analgesics were administered to Group TRA patients than to those in Group DEX $(P=0.001$; Table II). The number of shock waves administered per patient was comparable between the study groups, however, the shockwave intensity was higher in Group DEX patients $(P=0.02)$. Patients in Group DEX were more satisfied with their sedation and analgesia $(P=$ 0.02 and 0.01 , respectively) when compared with Group TRA patients (Table II). Furthermore, urologists were more pleased with the patient's level of sedation and analgesia when the DEX Group protocol was administered as opposed to the TRA Group pro- tocol $(P=0.001)$. Median OAA $/ \mathrm{S}$ scores decreased to ' 4 ' in Group DEX after 30 min of recovery but returned to the baseline level of ' 5 ' by the end of the first hour of recovery $(P=0.021$; Table III $)$. Comparison of psychomotor aspects of recovery using TD test revealed no differences between the two groups (Table III). There was no difference in the duration of stay in the recovery area among patients who received dexmedetomidine compared with those who received tramadol $(P=0.069$; Table II). There were no differences between the study groups with regard to $\mathrm{HR}, \mathrm{SBP}, \mathrm{DBP}, \mathrm{MAP}, \mathrm{SpO}_{2}$, or AAI values (Figure 2, available as Additional Material at www.cjajca.org). In addition, none of the patients in either group experienced nausea, vomiting, respiratory depression, or any other drug-related adverse effects.

\section{Discussion}

Dexmedetomidine is a highly selective $\alpha 2$-adrenoceptor agonist that possesses both sedative and analgesic properties, and yet has no respiratory depressant effects. ${ }^{6}$ Its use has been largely confined to the intensive care unit and to the operating room, and it has not been used previously for sedation and analgesia in patients undergoing ESWL. In contrast to dexmedetomidine, tramadol is a synthetic opioid that has decreased affinity for $\mu$-receptors. Thus it is also devoid of respiratory depressant effects. ${ }^{8}$ It has one tenth the potency of morphine and is as potent as meperidine. ${ }^{10}$ This randomized, double-blind clinical trial demonstrated that dexmedetomidine/morphine combination provided superior analgesia to tramadol/midazolam combination in patients who underwent ESWL for urinary tract calculi. Furthermore, patients' satisfaction was higher among those who received dexmedetomidine compared to those who did not. Although there was a slight imbalance in age between the study groups, all outcomes of interest did not change appreciably between the adjusted and the unadjusted analyses.

The observed differences between the study groups with regard to VAS scores, the number of PCA attempts made, and the amounts of supplemental analgesia administered both via the PCA machine and as rescue treatment provide evidence that patients who received tramadol were not as comfortable as those who received dexmedetomidine despite the fact that the tramadol PCA prescription was equipotent to that of morphine PCA and that both tramadol and morphine have the same latency and duration of action. ${ }^{10}$ This could be explained by the synergistic analgesic effects of dexmedetomidine and morphine which were administered to Group DEX patients. In support of 
this are the findings of Scheinin and colleagues who have demonstrated decreased fentanyl requirements by as much as $56 \%$ in patients premedicated with dexmedetomidine. ${ }^{15}$ Furthermore, a similar reduction in morphine requirement has been observed among intensive care unit patients who are sedated with dexmedetomidine. ${ }^{9}$ It is unlikely, however, that the sedative effect of dexmedetomidine per se was responsible for the apparent analgesic efficacy of the drug because patients who received tramadol were sedated similarly, albeit with midazolam: the AAI values were not different between the two groups (Figure 2, available as Additional Material at www.cja-jca.org), and were consistently above 70 which has been demonstrated to correspond to wakefulness. ${ }^{16}$ The observed initial increase in VAS scores over time (Figure 1) could be attributed to the incremental increase in shock wave intensity during the ESWL session. This was followed by a plateau between 30 and $45 \mathrm{~min}$, likely a reflection of reaching the maximum attainable shockwave intensity in each patient. The subsequent increase in VAS score in Group TRA and decrease in Group DEX, however, could be explained in part by the small number of patients reaching this point in time in both study groups (three patients in Group DEX and four patients in Group TRA).

The quality of analgesia was also better in Group DEX compared with Group TRA. This is evident from the fact that higher shockwave intensity was achieved in dexmedetomidine-treated patients than in tramadol-treated ones (Table II). In addition, satisfaction scores with regard to both pain management and sedation were higher among patients in Group DEX when compared with those in Group TRA. Also, urologists were more satisfied with the degree of patients' analgesia and sedation when dexmedetomidine was administered as opposed to tramadol. This could be attributed to the possibility that better pain control made patients in Group DEX to be more immobile and cooperative during ESWL compared with patients in Group TRA.

Although dexmedetomidine was superior to tramadol with regard to its analgesic effects, patients who received dexmedetomidine had a median length of stay of $85 \mathrm{~min}$ in the recovery area compared with $65 \mathrm{~min}$ for patients in Group TRA $(P=0.069)$. The lack of statistical significance reflects that this study was not powered to detect such a difference had it truly existed, as this was not the primary research question. It is likely that the delayed discharge among patients in Group DEX was due to the combined sedative effects of dexmedetomidine and morphine which were unmasked by the absence of the shockwaves' stimulus. In support of this is the observation that OAA/S scores were ' 5 ' in both groups upon arrival in the recovery area but decreased to '4' a half hour later in Group DEX patients compared with patients in Group TRA (Table III). However, OAA/S scores returned to baseline values by the end of the first hour of recovery which could be attributed to the waning of dexmedetomidine effects. In contrast, tramadol has minimal sedative effects which would explain the consistent OAA/S score of ' 5 ' observed throughout the recovery period, and the shorter discharge times seen among Group TRA patients. Interestingly, there were no differences in the TD test between the two study groups although $\mathrm{OAA} / \mathrm{S}$ scores differed in the early recovery period. One possible explanation for this is that the OAA/S test was consistently performed before the TD test; the latter test required patients to be awakened to perform the assigned task as opposed to being observed passively for the OAA/S assessment.

None of the patients in either study group had respiratory depression, defined as a respiratory rate $\leq 10$ breaths $\mathrm{min}^{-1}$, or any episode of desaturation $\left(\mathrm{SpO}_{2}<\right.$ 95\%). The latter could be attributed, at least in part, to the provision of supplemental oxygen to all study patients. Furthermore, both dexmedetomidine and tramadol are devoid of significant respiratory depressant effects which would largely explain the lack of respiratory adverse outcomes. Of particular interest, however, was the absence of nausea and vomiting among all study patients. This is in direct contrast with the results of Chia et al. who reported a $25 \%$ incidence of nausea and vomiting among patients who had received tramadol for ESWL. ${ }^{17}$ The observed discrepancy between the two studies cannot be explained by differences in drug dosage as patients in the current trial received far more tramadol than those in Chia's study. ${ }^{17}$ However, tramadol-treated patients in Chia's study received fentanyl as rescue treatment for pain and that could account for the increased incidence of nausea and vomiting. Whether the concomitant administration of midazolam with tramadol in the current study had an effect on preventing the occurrence of this adverse effect remains speculative.

One limitation of the current study is the lack of well-defined criteria for determining urologists' degree of satisfaction. Urologists were simply asked to rate their satisfaction with the patient's level of tolerance of ESWL on a seven-point scale. Although one could argue that this is not a validated scale, it was applied to both groups of patients and to the same group of urologists. Another limitation of the study is the use of actual patients' discharge times from the recovery area rather than patients' readiness for discharge using 
postanesthesia discharge criteria. It has been demonstrated that a difference between patients' readiness for discharge and actual discharge times does exist. ${ }^{18}$

In conclusion, this study demonstrates that dexmedetomidine in conjunction with morphine PCA provides better analgesia and patient satisfaction than tramadol/midazolam with tramadol PCA in patients undergoing ESWL for urinary tract calculi.

\section{Acknowledgements}

The authors acknowledge the help of Mr. Haitham Abdulmajeed in collecting the data. In addition, the authors are grateful to Professors Hisham Mosli, Hassan Farsi, and Mahmood Atwa and Dr. Abdulmalik Al-Tayeb, from the Department of Urology, and to the nursing staff of the ESWL unit for their support and enthusiasm.

\section{References}

1 Beloeil H, Corsia G, Coriat P, Riou B. Remifentanil compared with sufentanil during extra-corporeal shock wave lithotripsy with spontaneous ventilation: a double-blind, randomized study. Br J Anaesth 2002; 89: 567-70.

2 Irwin MG, Campbell RC, Lun TS, Yang JC. Patient maintained alfentanil target-controlled infusion for analgesia during extracorporeal shock wave lithotripsy. Report of investigation. Can J Anaesth 1996; 43: 919-24.

3 Joo HS, Perks WJ, Kataoka MT, Errett L, Pace K, Honey $R J$. A comparison of patient-controlled sedation using either remifentanil or remifentanil-propofol for shock wave lithotripsy. Anesth Analg 2001; 93: 1227-32.

4 Koch ME, Kain ZN, Ayoub C, Rosenbaum SH. The sedative and analgesic sparing effect of music. Anesthesiology 1998; 89: 300-6.

5 Jaakola $M L$, Salonen M, Lebtinen R, Scheinin $H$. The analgesic action of dexmedetomidine-a novel $\alpha 2$ adrenoceptor agonist-in healthy volunteers. Pain 1991; 46: $281-5$.

6 Hall JE, Uhrich TD, Barney JA, Arain SR, Ebert TJ. Sedative, amnestic, and analgesic properties of smalldose dexmedetomidine infusions. Anesth Analg 2000; 90: 699-705.

7 Mildh LH, Leino KA, Kirvela OA. Effects of tramadol and meperidine on respiration, plasma catecholamine concentrations, and hemodynamics. J Clin Anesth 1999; 11: 310-6.

8 Tarkkila P, Tuominen M, Lindgren L. Comparison of respiratory effects of tramadol and pethidine. Eur J Anaesthesiol 1998; 15: 64-8.

9 Triltsch AE, Welte M, von Homeyer P, et al. Bispectral index-guided sedation with dexmedetomidine in inten- sive care: a prospective, randomized, double blind, placebo-controlled phase II study. Crit Care Med 2002; 30: 1007-14.

10 Lee CR, McTavish D, Sorkin EM. Tramadol. A preliminary review of its pharmacodynamic and pharmacokinetic properties, and therapeutic potential in acute and chronic pain states. Drugs 1993; 46: 313-40.

11 Ge SJ, Zhuang XL, Wang YT, Wang ZD, Li HT. Changes in the rapidly extracted auditory evoked potentials index and the bispectral index during sedation induced by propofol or midazolam under epidural block. Br J Anaesth 2002; 89: 260-4.

12 Struys MM, Jensen EW, Smith W, et al. Performance of the ARX-derived auditory evoked potential index as an indicator of anesthetic depth. A comparison with bispectral index and hemodynamic measures during propofol administration. Anesthesiology 2002; 96 : 803-16.

13 Chernik DA, Gillings D, Laine H, et al. Validity and reliability of the Observer's Assessment of Alertness/Sedation scale: study with intravenous midazolam. J Clin Psychopharmacol 1990; 10: 244-51.

14 Newman MG, Trieger N, Miller JC. Measuring recovery from anesthesia-a simple test. Anesth Analg 1969; 48: 136-40.

15 Scheinin H, Jaakola $M L$, Sjivall S, et al. Intramuscular dexmedetomidine as premedication for general anesthesia: a comparative multicenter study. Anesthesiology 1993; 78: 1065-75.

16 Litvan H, Jensen EW, Revuelta M, et al. Comparison of auditory evoked potentials and the A-line ARX index for monitoring the hypnotic level during sevoflurane and propofol induction. Acta Anaesthesiol Scand 2002; 46: $245-51$.

17 Chia Y, Liu K. Prospective and randomized trial of intravenous tenoxicam versus fentanyl and tramadol for analgesia in outpatient extracorporeal lithotripsy. Acta Anaesthesiol Sin 1998; 36: 17-22.

18 Alhashemi JA, Miller DR, O'Brien HV, Hull KA. Costeffectiveness of inhalational, balanced and total intravenous anaesthesia for ambulatory knee surgery. Can J Anaesth 1997; 44: 118-25. 